\section{|||||||||||||||||||||||||||||||||||||||||||||||||||||||,}

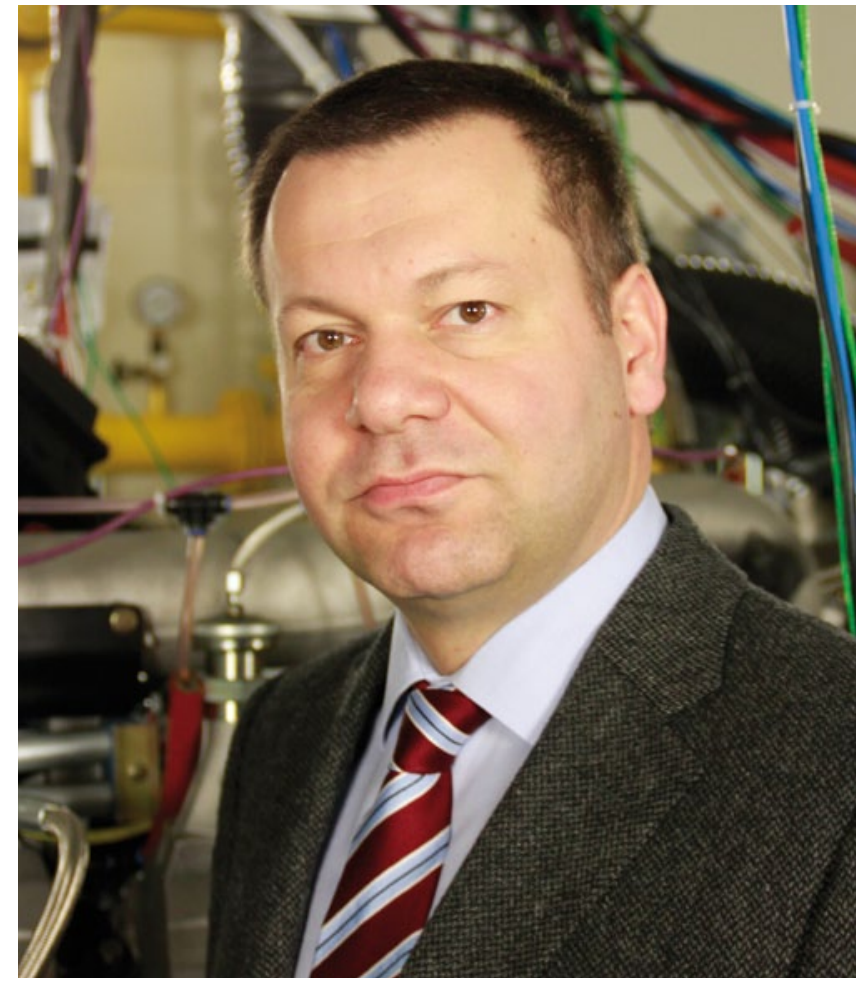

DR. ANDREAS

\section{PFEIFER}

Hauptabteilungs-

leiter Entwicklung

Dieselmotoren

bei Liebherr

Machines Bulle

SA (Schweiz)

DR. ANDREAS

PFEIFER

Engineering

Director Diesel

Engines at

Liebherr

Machines Bulle

S.A. (Switzerland)

\title{
EMISSIONSREDUZIERUNG BEI BAUMASCHINEN
}

Bei der Emissionserfüllung haben die Industriemotoren deutlich aufgeholt und annähernd einen Gleichstand gegenüber Pkw und Nutzfahrzeug bezüglich einzuhaltender Grenzwerte und somit der erforderlichen Technik erreicht. Eine besondere Randbedingung für die Entwicklung von Baumaschinenmotoren stellt die hohe Variantenvielfalt bei kleiner Stückzahl, deutlich herausforderndere Betriebsbedingungen, oftmals ungenügende Wartung und sehr lange Motorlebensdauern dar. Die unterschiedlichen Geschwindigkeiten der Emissionsregulierung zwischen Europa, USA, Südkorea und Japan einerseits und dem Rest der Welt andererseits, in dem aber das Hauptwachstum des Baumaschinenmarkts stattfindet, führt zu einer Abkopplung der Märkte und dem Erfordernis einer Parallelentwicklung, die eine Kostenexplosion für die Motoren- und Gerätehersteller nach sich zieht.

Als Motorhersteller innerhalb eines großen Baumaschinenkonzerns sehen wir uns für diese Herausforderungen mit einem systemischen Ansatz gut gewappnet: Für die kommenden Emissionsanforderungen Stufe VI / Tier 4 final und die diskutierte Stufe V entwickeln wir modulare, skalier- und kombinierbare Technologiepakete, die auch eine Variante für Schwellenländer einschließt. Die dazu erforderlichen Kerntechnologien Einspritzsystem, Regelung (Steuergerät und Funktionalität), Abgasnachbehandlung im eigenen Haus zu haben, ist ein unschätzbarer Vorteil. Durch die enge Verbindung zu den Geräteherstellern ist die Antriebsstrangintegration ins Gerät mit der Zielsetzung eines optimalen Verbrauchs des Endgeräts gewährleistet. 